\title{
Increasing fatal AA amyloidosis in hunting falcons and how to identify the risk: a report from the United Arab Emirates
}

\begin{abstract}
In hunting falcons, a fatal syndrome of wasting, weight loss, green mutes and, finally, sudden death of emaciated birds has been observed in the United Arab Emirates (UAE). Histological examination using Congo red has revealed amyloid in most organs, in particular in the liver, spleen, kidney, and adrenal glands. Moreover, a retrospective study revealed amyloidosis in 100 cases among a total of 623 necropsied falcons between August 1995 and March 2004 in Dubai/UAE (16\%; varying from 8 to 30\% in different raptor bird species). The amyloid was immunohistochemically classified as amyloid A (AA), which was confirmed by Western blot analysis and $\mathrm{N}$-terminal amino acid sequence analysis, suggesting it to be secondary to a chronic inflammatory process. Retrospective analysis has indicated a significantly increased prevalence of bumble foot and visceral gout among falcons with amyloidosis. In addition, a significant increase of amyloidosis from $5.6 \%$ of necropsied falcons with amyloidosis in 1995 to $40.0 \%$ in 2004 has been noticed. Finally, a semi-quantitative serum test for falcon serum amyloid A (f-SAA) has been developed. Among 38 falcons with fatal AA amyloidosis, f-SAA was increased pathologically in 36 , whereas f-SAA was elevated in only one of 15 apparently disease-free falcons $(\mathrm{p}<0.001)$. This significant result indicates that a normal f-SAA will indicate a minimal or even absent risk of succumbing to AA amyloidosis.
\end{abstract}




\title{
Increasing fatal AA amyloidosis in hunting falcons and how to identify the risk: a report from the United Arab Emirates
}

\author{
MIRJAM RICARDA HAMPEL ${ }^{1,2}$, JOERG KINNE $^{2}$, ULRICH WERNERY ${ }^{2}$, \\ ANDREAS POSPISCHIL ${ }^{1}$, JOSEF KELLERMANN ${ }^{3}$, \& REINHOLD PAUL LINKE ${ }^{4}$ \\ ${ }^{1}$ Institute of Veterinary Pathology, University of Zürich, Zürich, Switzerland, ${ }^{2}$ Central Veterinary Research Laboratory, UAE- \\ Dubai, United Arab Emirates, ${ }^{3}$ Max Planck Institute of Biochemistry, Martinsried, Germany, and ${ }^{4}$ Reference Center of \\ Amyloid Diseases, amYmed, Innovation Center of Biotechnology, Martinsried, Germany
}

Keywords: $A A$ amyloidosis, amino acid sequence, bumble foot, gout, gyr falcon, immunohistochemistry, serum amyloid- $A$ concentration

\begin{abstract}
Abbreviations: $A A=$ amyloid $A ; f-A A=$ falcon $A A ; A \beta_{2} M=$ amyloid of $\beta_{2}$-microglobulin origin; $A L \lambda(\kappa)=$ amyloid of immunoglobulin $\lambda(\kappa)$-light chain origin; $C R=$ Congo red; $C R F=$ Congo red fluorescence; $C V R L=$ Central Veterinary Research Laboratory in Dubai; $G B=$ green birefringence; $k D a=$ Kilodalton; $N C=$ nitrocellulose; $P A P=$ peroxidase-antiperoxidase; $S A A=$ serum amyloid $A$ protein; $f-S A A=$ falcon $S A A ; S D S-P A G E=$ sodium dodecyl sulfate polyacrylamide electrophoresis; $U A E=$ United Arab Emirates; KIR and HAR = artificial acronyms of patients' names
\end{abstract}

\begin{abstract}
In hunting falcons, a fatal syndrome of wasting, weight loss, green mutes and, finally, sudden death of emaciated birds has been observed in the United Arab Emirates (UAE). Histological examination using Congo red has revealed amyloid in most organs, in particular in the liver, spleen, kidney, and adrenal glands. Moreover, a retrospective study revealed amyloidosis in 100 cases among a total of 623 necropsied falcons between August 1995 and March 2004 in Dubai/UAE (16\%; varying from 8 to $30 \%$ in different raptor bird species). The amyloid was immunohistochemically classified as amyloid A (AA), which was confirmed by Western blot analysis and N-terminal amino acid sequence analysis, suggesting it to be secondary to a chronic inflammatory process. Retrospective analysis has indicated a significantly increased prevalence of bumble foot and visceral gout among falcons with amyloidosis. In addition, a significant increase of amyloidosis from $5.6 \%$ of necropsied falcons with amyloidosis in 1995 to $40.0 \%$ in 2004 has been noticed.

Finally, a semi-quantitative serum test for falcon serum amyloid A (f-SAA) has been developed. Among 38 falcons with fatal AA amyloidosis, f-SAA was increased pathologically in 36, whereas f-SAA was elevated in only one of 15 apparently disease-free falcons $(p<0.001)$. This significant result indicates that a normal f-SAA will indicate a minimal or even absent risk of succumbing to AA amyloidosis.
\end{abstract}

\section{Introduction}

Falconry has an important tradition in the Arabic world. Frederick II of Hohenstaufen has canonized it in Europe in his famous masterwork [1], which summarizes the state of falconry in the 13th century. Today, half of the falconers alone are operative in the Middle East. The importance of falconry is evident in particular from the fact that Islam itself permits falcons for hunting.

In several veterinary clinics of the United Arab Emirates (see Acknowledgement section), an increasing number of cases involving a fatal wasting disease in falcons has been noticed during the last years and its cause has initiated some concerns. Examinations have revealed amyloid A (AA) amyloidosis to be the cause of this disease.

Systemic AA amyloidosis has been reported in most mammals, including humans, and in some birds. In general, this disease is the result of longlasting inflammations in humans [2-5] and in animal species [6-10].

Correspondence: Dr. Reinhold P. Linke, Reference Center of Amyloid Diseases, amYmed, Innovation Center of Biotechnology, Am Klopferspitz 19, D-82152 Martinsried, Germany. Tel: +49-89-520-12-368. Fax: +49-89-523-89-013. E-mail: linke@amymed.de; www.amymed.de 
AA amyloidosis (as other classes of amyloid) is diagnosed on tissue sections through the recognition of extracellular protein deposits, after using the Congo red (CR) staining method [11]. Although its pathogenesis is not completely understood, reducing the inflammatory load can arrest and even prevent its progression in humans $[3,4,12,13]$.

In mammals, AA amyloidosis has been reported in canines [14,15], felines [16-18], bovines [19,20], ovines [21,22], porcines [23], equines [24], lagomorphs [25], and other species [6,26], besides other amyloid types [10].

In birds, only the AA type of amyloid has been reported and it was found to be chemically homologous to mammalian AA. Avian AA protein has been sequenced in ducks [27-29], geese [30], and chickens [31]. In addition, avian AA amyloidosis was also diagnosed immunohistochemically in a variety of bird families [32,33], although an earlier report on amyloidosis in the falconiformes did not include its classification [34].

In this report, we have analyzed the chemical nature of amyloid in falcons and identified its cause as driven by inflammation. In addition, evidence for a genetically transmitted factor has been presented and infectious agents causing falcon AA amyloidosis have been identified. Finally, for early diagnosis and therapeutic considerations, a serum test is reported, which will become of value in identifying the risk for falcons of succumbing to the fatal AA amyloidosis.

\section{Materials and methods}

Falcons and tissue sections

Necropsies of 623 falcons were conducted at the Central Veterinary Research Laboratory (CVRL) in Dubai/UAE between August 1995 and March 2004. The falcons were brought to the CVRL from other Arabic institutions which are mentioned in the Acknowledgement section.

A review of the charts of all 623 falcons was made concerning their inflammatory conditions and concerning their microbial infections by laboratory standard methods.

Organs of all necropsied falcons were fixed in $10 \%$ formalin (buffered $4 \%$ formaldehyde) and embedded in paraffin. For histopathological examination, 4-6 $\mu \mathrm{m}$ tissue sections were prepared.

\section{Diagnosis of amyloid}

All sections were stained with hematoxylin/eosin (HE) [35] and with CR [11]. Amyloid was examined microscopically in bright light for the presence of amorphous, eosinophilic, extracellular material, as revealed by HE staining, for its affinity for CR, for its green birefringence (GB) in polarized light [11] and for its orange-red Congo red fluorescence (CRF) in blue excitation [36].

Such tissue samples from 100 falcons with amyloid (out of 623 necropsies) were examined as liver, kidney, adrenal glands, spleen, intestine and other organs. In addition, 43 liver biopsies of falcons without amyloidosis were also available, which were processed by the same procedure and examined as controls.

Electron microscopy was performed on formalinfixed and paraffin-embedded hepatic amyloid containing tissue of a Gyr falcon re-embedded in Araldite by standard techniques. Ultrathin sections $(50 \mathrm{~nm})$ were placed on Pilioform-covered nickel grids, mesh 150 , contrasted with uranyl acetate and lead citrate, and photographed with a Zeiss electron microscope.

\section{Classification of the falcon amyloid}

Classification of the falcon amyloid was performed immunohistochemically on paraffin sections using the peroxidase-anti-peroxidase (PAP) system of Sternberger with $\mathrm{H}_{2} \mathrm{O}_{2}$ as a substrate and aminoethylcarbazole as a chromogen as described [36-38]. The antibodies applied were murine monoclonal mc1 (also available from Dako) and mc29 (known to cross-react with most species) directed against human AA [37] and three polyclonal rabbit antibodies directed against human and bovine AA [32], and against murine AA [7]. Included was also a rabbit anti-human AL $\lambda$ (HAR) antibody known to cross-react with AL $\lambda$ amyloid of humans, canines, felines, and equines [39-41].

\section{Molecular size of falcon- $A A$ and its protein precursor falcon serum amyloid $A$ protein}

To identify the molecular size of the falcon AA (f-AA)protein and the falcon serum amyloid A protein (fSAA), serum samples of falcons with AA amyloidosis and the f-AA extracted from a formalin-fixed liver [42] were separated using sodium dodecyl sulfate-polyacrylamide gel electrophoresis (SDS-PAGE) at 12.5\% [43]. Controls were serum samples of falcons, which were apparently disease-free. Bromphenol blue as tracking dye and marker proteins of known size were run in parallel. The position of the size markers was used to create a calibration curve by which the molecular weights of the protein bands were estimated.

The resulting gels were either stained with Coomassie blue or examined by Western blotting. After electrotransfer onto nitrocellulose (NC, B 86; Schleicher \& Schüll, Dassel/Germany), immunodetection followed [44].

\section{Partial amino acid sequence of the f-amyloid protein}

AA protein was extracted from a formalin-fixed, paraffin-embedded falcon hepatic tissue loaded with 
amyloid, dialyzed against water and lyophilized as published [42].

For N-terminal amino acid sequence analysis, the extracted proteins were separated by SDS-PAGE $(15 \%)$ and then electro-transferred onto a polyvinylidene difluoride membrane [45]. The blotted protein bands were stained with Coomassie blue for $1 \mathrm{~min}$. After destaining, the bands were excised and sequenced on a Procise 492 pulsed liquid phase sequencer (Applied Biosystems, Foster City, CA). For analyzing internal peptides, in situ digestion of the proteins was performed by the method of Patterson [46] using endoproteinase LysC. Proteolytic fragments were separated by high-performance liquid chromatography (Hewlett Packard 1100) on a Purosphere RP18 reversed-phase column (Merck, Darmstadt, Germany) ( $1 \mathrm{~mm}$ by $150 \mathrm{~mm}$ ). Solvent A was $0.1 \%$ trifluoroacetic acid, and solvent $\mathrm{B}$ was $0.08 \%$ trifluoroacetic acid in acetonitrile. The gradient was 0-60\% solvent B over a period of $90 \mathrm{~min}$ at a flow rate of $60 \mu \mathrm{l} / \mathrm{min}$. The peptides were sequenced [47] on a Procise 492 sequencer according to the manufacturer's instructions.

For sequence queries, Basic Local Alignment Search Tool Protein Query (BLASTP) [48] was applied searching SwissProt databases.

Detection and quantification of the falcon serum amyloid A protein

Blood samples. Blood serum was available from all 40 falcons in which diagnosis of amyloidosis had been made on bioptic and autoptic samples. Blood samples were taken from the vena ulnaris with a $25 \mathrm{G}$ needle $(0.50 \mathrm{~mm} \times 16 \mathrm{~mm})$ under Isoflurane (IsoFlu Abbott, Laboratories, Queensborough, UK) anesthesia. Additional sera were available from 43 apparently disease-free falcons. The blood was allowed to clot at room temperature for $2 \mathrm{~h}$ and the clot was sedimented at $800 \mathrm{~g}$ for $10 \mathrm{~min}$. The serum was frozen immediately and stored at $-20^{\circ} \mathrm{C}$.

\section{Micro-ELISA}

Dotblot-Micro-ELISA for falcon serum amyloid $A$ protein. The f-SAA, was semi-quantitated using the dot immunoassay [49]. Control antigen was pure human AA, which was prepared after water extraction of native amyloid fibrils from frozen tissue as published [50]. The pure fibril monomeric AA (KIR) was isolated by gel filtration on Sephadex G100 in $6 \mathrm{M}$ guanidine- $\mathrm{HCl}$ according to Ref. [3] yielding a single band of $8.6 \mathrm{kDa}$ as proven by SDSPAGE electrophoresis [43]. The N-terminal amino acid sequence of this control protein showed the known sequence of AA according to Ref. [2]. This pure AA (KIR) protein at $100 \mu \mathrm{g} / \mathrm{ml}$, under $0.03 \mathrm{M}$ barbital puffer, $\mathrm{pH} 8.6$, served as a standard.
The standard AA protein was run in parallel in a series of known protein concentrations in the same assay. The blotted proteins were immunochemically identified using the PAP technique as mentioned above. The f-SAA concentration could be estimated semi-quantitatively from the intensity of staining, which was compared by inspection with that of the standard AA protein of known amounts.

\section{Statistical analysis}

The statistical analysis was carried out using Microsoft Excel and Stratgraphic plus Version 5. ChiSquare 'Goodness of Fit' test was used to assess the independence of amyloid occurrence of falcon species and diagnosed disease [51]. Others were carried out according to Ref. [52] with comparable results (by courtesy of Prof. R. Schuster).

\section{Results}

Novel falcon disease

The disease commenced with an uncharacteristic syndrome including more slow reactions and the appearance of a possible type of depression (Figure 1), followed by clinical signs presenting as a

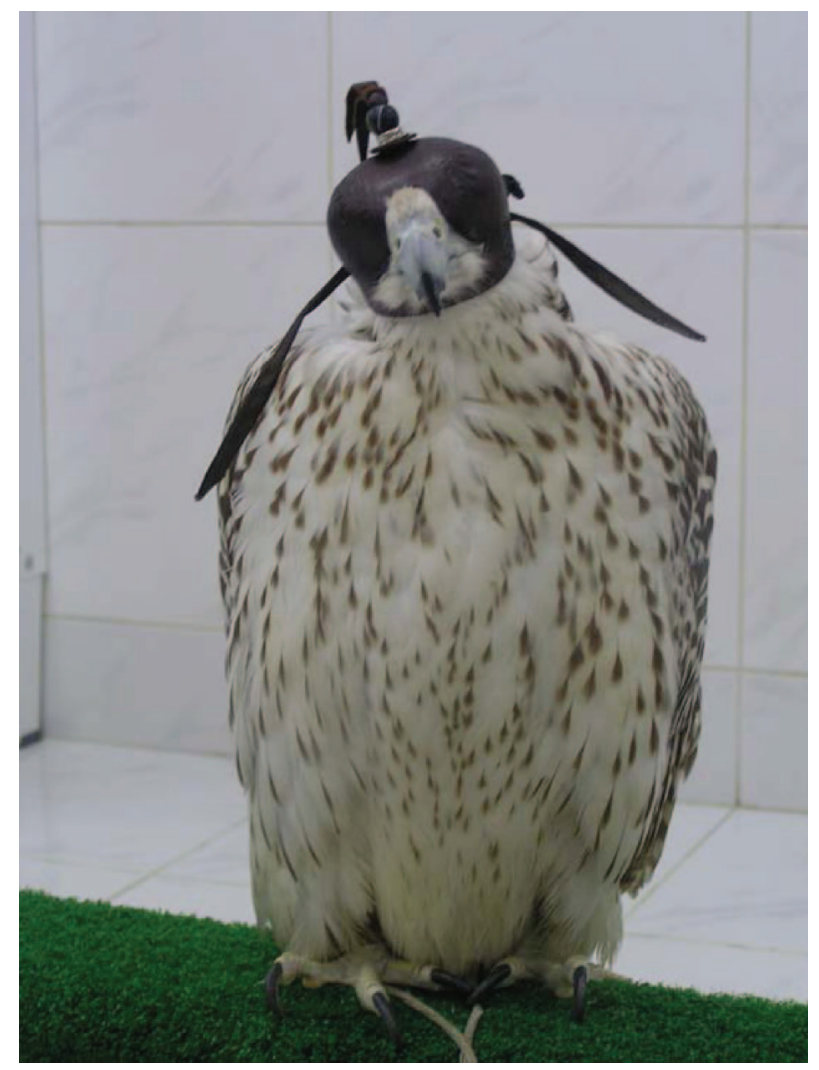

Figure 1. Lethargic and depressed appearance of a gyr falcon affected with AA amyloidosis (2-year-old female, diagnosis through liver biopsy). 
reduction of appetite, fatigue, and unwillingness to fly. Later, these signs worsened, resulting ultimately in a severe apathy extending to a lack of flying, complete loss of appetite, followed by significant weight loss, and green mutes, a syndrome which was often followed by sudden death associated with severe emaciation.

\section{Necropsy and the diagnosis of amyloid}

Post-mortem examination revealed significant enlargement of involved organs with discoloration and a waxy, easily breakable consistency which was a major characteristic of many falcons with amyloidosis, macroscopically (Figure 2).

Amyloid was detected histologically in paraffin sections after CR staining in $100(16.0 \%)$ falcons out of a total of 623 necropsies. As illustrated in Figure 3a, a pinkish red coloration marks the amyloid after CR-staining, whereas the GB in polarized light identifies amyloid (Figure 3b). In Figure 3c, the highly sensitive CRF is shown that identifies the entire amyloid mass at the same time.

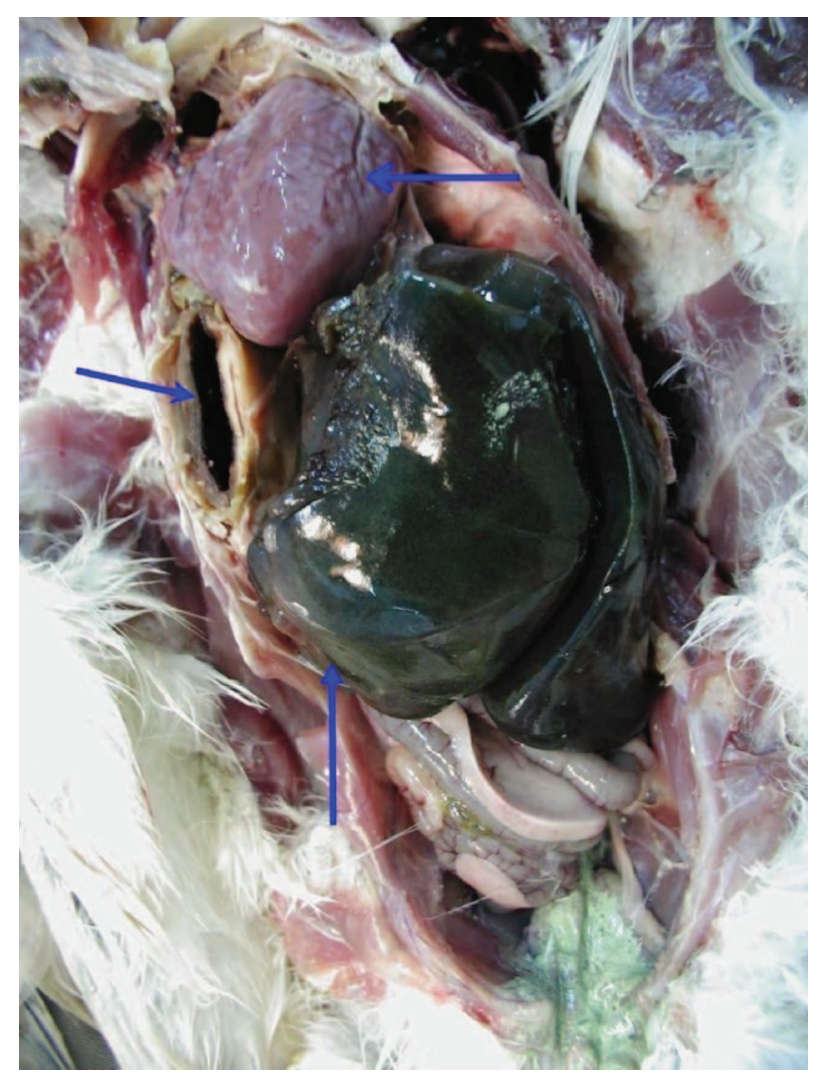

Figure 2. Necropsy of a falcon with amyloidosis. Diagnosis of amyloid through histological evaluation (see Figure 3). Massive hepatomegaly with typical greenish-brownish discoloration of the liver (bottom arrows). Fibrinous perihepatitis and pericarditis. The heart is of normal size (top arrow). In this falcon, a Pseudomonas aeruginosa infection and chronic aspergillosis (left arrow) was diagnosed.
In 86 examined livers, liver being the main target organ, massive amyloid was recorded out of the 100 falcons. In the remaining 14 falcons without data on hepatic histology in the charts, amyloid was diagnosed by way of such other organs as kidneys, spleen, adrenals, pancreas, and gut. The amyloid was mainly found as an amorphous, eosinophilic, extracellular material in the capillary space of Disse, resulting in atrophy of the hepatocytic sheets in some severe cases. Renal amyloid was detected in the cortical and peritubular interstitium (Figure 3f), whereas the glomeruli remained largely amyloid-free.

Similar to AA amyloid deposits of many other species, the falcon AA amyloid is a systemic, predominantly vascular amyloidosis starting at the subendothelial site. In addition, a chronic inflammation was indicated in many organs by slight to moderate infiltration of some perivascular sheets with mononuclear cells. The nervous system (brain, cerebellum, medulla oblongata, spinal cord) was not affected.

Electron microscopy revealed characteristic amyloid fibrils of $\sim 10 \mathrm{~nm}$ diameter. The fibrils were straight, unbranched, and of undetermined length. They were deposited as dense bundles of more or less parallel fibrils (Figure 4). At other places they were deposited more irregularly (not shown).

\section{Classification of the falcon amyloid}

This chemical amyloid class was then identified immunohistochemically in liver, spleen, and kidney of four falcons as being of the AA type. In three livers without amyloidosis no reaction was seen. An example is illustrated in Figure 3. The main immunohistochemical reaction was provided by the monoclonal AA antibody mc29 which shows strong staining of hepatic (Figure 3e) and renal (Figure 3f) amyloid, whereas monoclonal AA (mc1)-antibody was unreactive (negative control, not shown). In addition, polyclonal AA antibodies against mammals (cow, mouse, and humans) did not cross-react with falcon AA amyloid. Moreover, the anti-human AL $\lambda$ (HAR) also failed to react with falcon amyloid as well (Figure 3d) indicating strongly that falcon amyloid is not of the AL $\lambda$ amyloid class. Finally, this falcon amyloid was shown to be permanganate sensitive [53].

\section{Molecular size of falcon serum amyloid $A$ protein and falcon- $A A$}

To identify the molecular size of f-SAA, each of some falcon sera were separated by SDS-PAGE and the bands were examined for AA antigenic reactivity using Western blotting with mc29. The Coomassie blue-stained size-separated bands (Figure 5, left) showed a difference in the low-molecular weight 

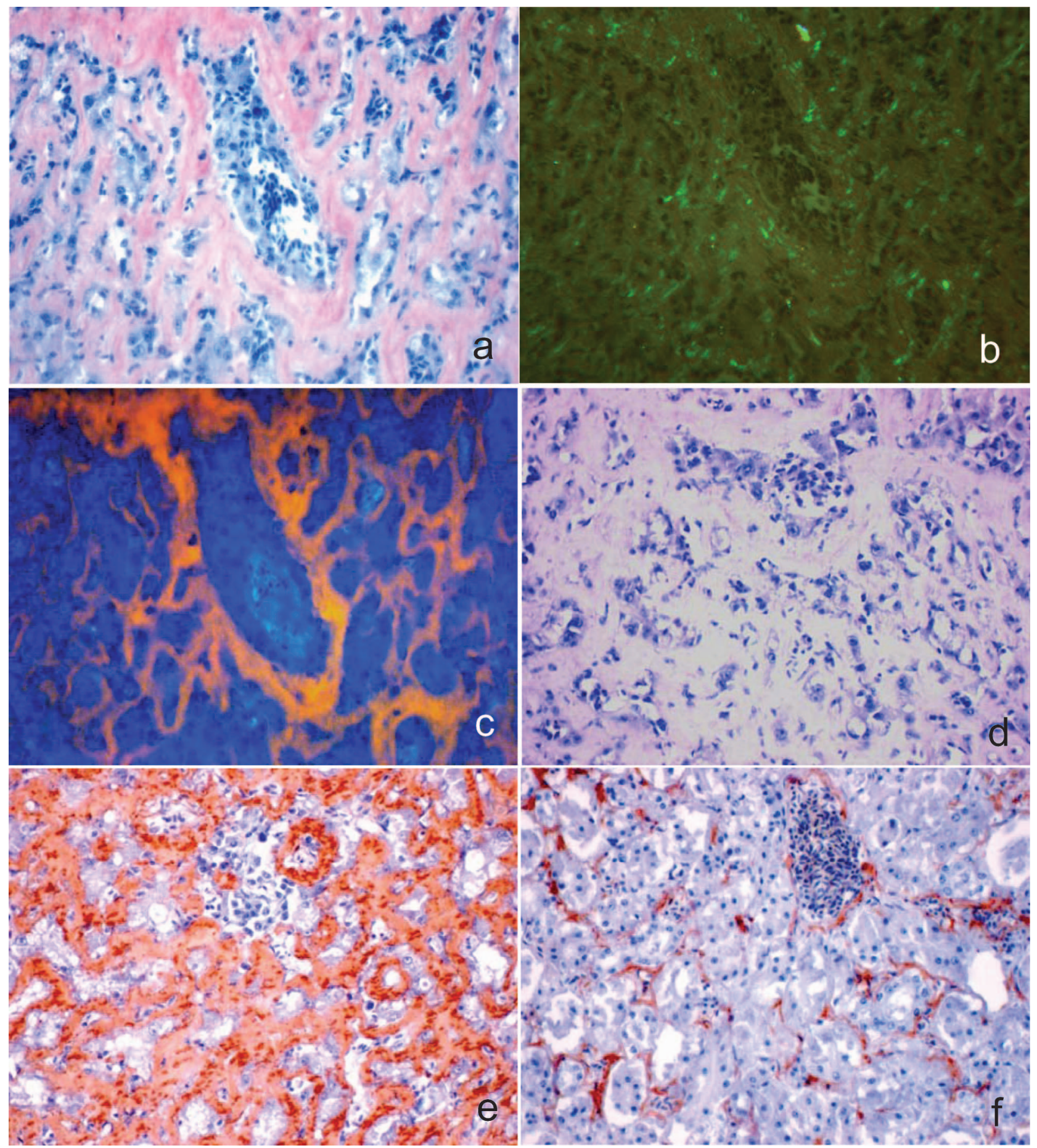

Figure 3. Diagnosis and classification of falcon amyloid on paraffin sections (Counterstain hematoxylin; magnification $160 \times$ ). (a-c) Diagnosing amyloid using the Congo red procedure. (a) Liver infiltrated with masses of amorphous, eosinophilic, extracellular material along the capillary space of Disse. Amyloid is indicated by the pinkish coloration. (b) The same section as in a. in polarized light. The green birefringence identifies amyloid. However, due to the 'polarization shadow' [36], only a fraction of the amyloid mass reveals this pathognomonic trait at a defined position of the polarization filters. Different parts of the amyloid mass will show this trait after turning the slide table. (c) The same section as in (a) and (b) in fluorescent light. Different from the situation in (b), the whole amyloid mass is illuminated at the same time. The amyloid appears orange-red using excitation in blue light with a barrier filter, that permits the green to red light to pass; for FITC (fluorescein isothiocyanate) [36]. (d-f) Immunohistochemical identification of falcon amyloid as AA type. (d) Liver amyloid immunohistochemically negative control reaction using anti-AL $\lambda$ (HAR) as primary antibody. (e) Liver, immunohistochemically stained with anti-AA (mc29) reveals a strong reaction of all amyloid deposits. Brown-reddish coloration marks the amyloid. (f) Kidney, immunohistochemical staining of peritubular and interstitial amyloid at moderate extent. (Note the characteristic intravasal avian nucleated erythrocytes, which are also seen in a-e). 
region pointing to a faint band in the acute phase serum (see arrow in lane 2) in contrast to the normal falcon serum (lane 1). The following immunochemical analysis of this band revealed a single very strong reaction with mc29 in full acute phase serum which identified an AA-antigenic protein of $11.0 \mathrm{kDa}$ which represents f-SAA (Figure 5 right, lane 2, see arrow). In addition, a faint band of the same size is also seen in normal falcon serum (Figure 5, right, lane 1) which represents the normal f-SAA. The molecular weight

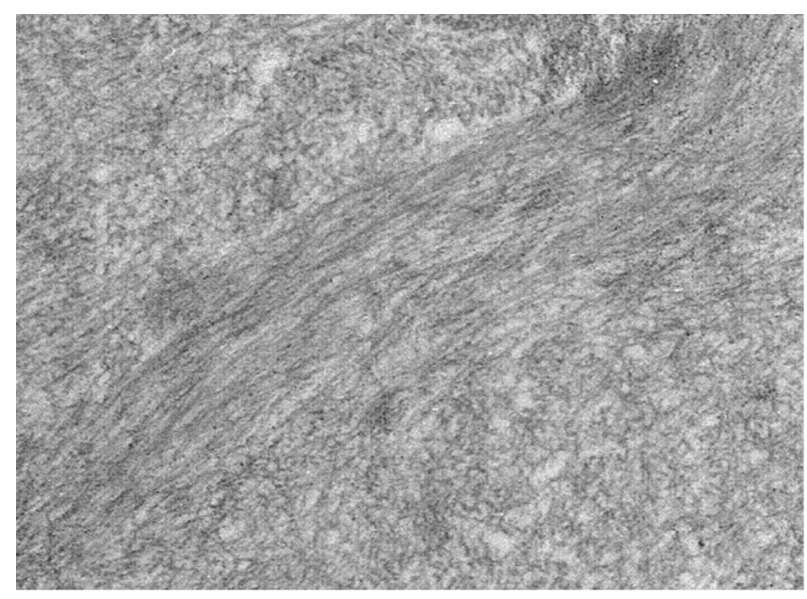

Figure 4. Electron microscopy of hepatic falcon amyloid fibrils are seen arranged in bundles (longitudinal and perpendicular view; diameter of the amyloid fibrils approximately $10 \mathrm{~nm}$ ).

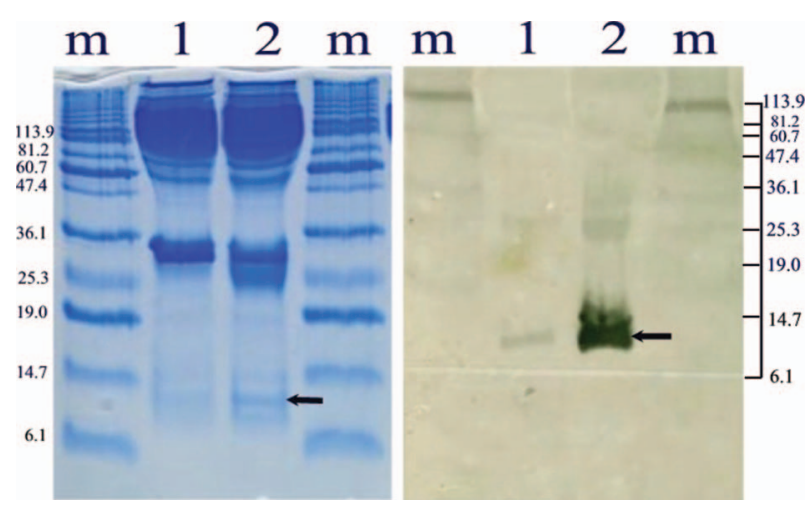

Figure 5. Identification of f-SAA using size separation followed by Western blotting. Left: SDS-PAGE separation of normal falcon serum without (lane 1) and serum of another falcon with an acute phase reaction and amyloidosis (lane 2). $\mathrm{m}$ represents molecular weight markers. Coomassie blue staining of proteins. Arrow points to a low-molecular weight protein in the region of f-SAA (note the difference between lane 1 and 2 with an increase of the concentration of a protein at the $11.0 \mathrm{kDa}$ position). Right: SDS-PAGE separation as performed in Left followed by Western blotting using anti-AA (mc29). In normal falcon serum (lane 1) at the position of $11.0 \mathrm{kDa}$ a trace of f-SAA can be identified whereas at the same position in an falcon acute phase serum a very intensive reaction can be seen indicating a significant increase of $\mathrm{SAA}$ at the same position of $11.0 \mathrm{kDa}$ in lane 2 (see arrow). As molecular weight markers vanish during Western blotting, the exact position of the marker ladder has been copied from the NC-membrane after electrotransfer before Western blotting. of the $\mathrm{f}-\mathrm{AA}$ protein was determined likewise. Major bands of 8,16 , and $24 \mathrm{kDa}$ size (with a reduction in concentration, in that order) were labelled strongly with mc29 immunochemically (not shown).

\section{$N$-terminal amino acid sequence}

The N-terminal amino acid sequence analysis was determined from peptides of the $8 \mathrm{kDa}$ moiety isolated from the f-AA protein as shown in Figure 6. In addition, the falcon sequence was compared with the five published sequences that have been determined from tissue amyloid protein and/or from the nucleotide sequences of ducks, geese, and chickens [27-31] and compared with humans [54].

The obtained sequence of 23 amino acids commences at position 1 of the $\mathrm{N}$-terminus of the mature protein as compared with the other sequences of other birds. The N-terminal heptapeptide has no homology with the sequence of AA amyloid proteins of other avian and mammalian species, including that of humans [21,42,54]. In addition, a Basic Local Alignment Search Tool (BLAST) search did not reveal any hint to its significance. By the way, the subsequent sequence at position 8 and 9 is identical with that of the other birds, but not with that of humans and other mammals [21]. However, phenylalanine at position 10 is identical in most if not all AA proteins $[21,42,54]$, and from this position on homology is shown till the end at position 23 of the falcon peptide.

The 8-23 segment represents a relatively variable region of avian AA when compared with the other more complete sequences of 109 amino acids of ducks and geese [27-30], of 106 amino acids in a duck [28] and 57 residues in a chicken AA protein (31). So, within the sequence from position 24 to the C-terminus, only one single amino acid exchange occurs at position 70 between ducks and geese (marked in red) (Figure 6). Similarly invariable is the leader sequence between ducks and geese, with only one exchange at position -8 (A-S) (marked in red) due to one nucleotide exchange. The number of identical amino acids of the falcon sequence 8-23 to the homologous sequence of ducks, geese and chickens are numbered 13, 12 and 10, respectively.

In addition, the three amino acid exchanges identified as compared with ducks are at position 12 (falcon-duck: W-L), 15 (V-A), and 22 (Y-L), and are caused by single nucleotide exchanges in the first two, and two exchanges in the latter amino acid exchange. Although these three exchanges are conservative, a slight increase of hydrophobicity in the falcon sequence as compared with that in the duck could be inferred.

Finally, the amino acids marked in green in the human AA protein indicate the three positions in 


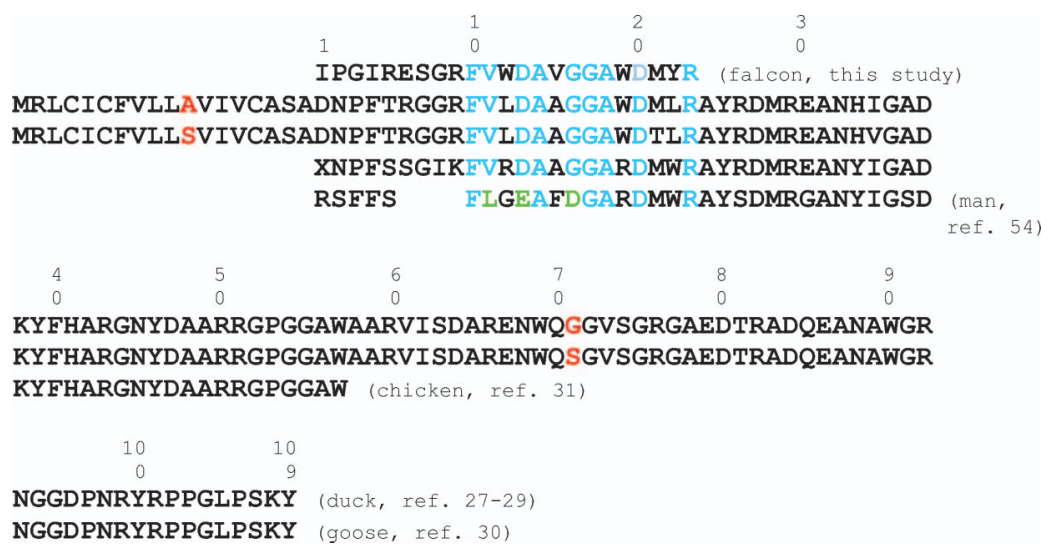

Figure 6. N-terminal amino acid sequence of falcon AA amyloid. Comparison with AA proteins reported from other birds and humans. Blue: identity of falcon AA protein with duck, goose, chicken and humans. Red: single amino acid exchanges in the signal peptide and at position- 8 and at position 70 of the mature protein in duck and goose. Green: Three human amino acids different from falcon, chicken, duck, and goose.

which the human differs from the avian constant positions within the 23-mer sequenced as shown in Figure 6.

Susceptibility of the different falcon species to succumb to AA amyloidosis

The data on the prevalence of amyloidosis among the different falcon species are shown in Table I as compiled from the charts. It is clear from these data that the pure gyr falcons are the most susceptible as $40(30.0 \%)$ out of the 132 examined gyr falcons succumbed to amyloidosis, whereas only 18 of the 142 peregrine falcons $(12.7 \%)$ were affected. The most resistant were the saker falcons with only $8.7 \%$ diseased by amyloidosis. Interestingly, the gyr hybrids were remarkably protected $(16.7 \%)$, as compared with the pure gyr falcons. Finally, falcons whose species were not recorded (because they were possibly the smallest and the least conspicuous ones) belong to the most resistant class.

Statistical analysis revealed that only the prevalence of amyloidosis in the gyr falcon related to this species was highly significant $(p<0.001)$. When the gyr falcons were removed before a second analysis, the remaining cohort of falcon species (peregrine, saker, gyr hybrids and unknown falcon species) did not show a statistically significant difference to the occurrence of amyloidosis demonstrated in the remaining species $(p=0.1507)$.

\section{Inflammatory load in falcons with and without amyloidosis}

To find out which of the common inflammatory states, such as chronic, visceral gout, aspergillosis or the numerous infectious agents, are prevalent in falcons with amyloidosis, as compared with those without any chronic inflammation, all available data
Table I. Prevalence of amyloidosis within the different falcon species.

\begin{tabular}{lccccr}
\hline & \multicolumn{2}{c}{ All autopsies } & & \multicolumn{2}{c}{$\begin{array}{c}\text { Autopsies with } \\
\text { amyloidosis }\end{array}$} \\
\cline { 2 - 3 } \cline { 6 - 6 } Falcon species & Number & $\%$ & & Number & $\%$ \\
\hline Gyr & 132 & 21.2 & & 40 & 30.3 \\
Gyr hybrid & 150 & 24.1 & & 25 & 16.7 \\
Peregrine & 142 & 22.8 & & 18 & 12.7 \\
Saker & 80 & 12.8 & & 7 & 8.7 \\
Unknown/other & 119 & 19.1 & & 10 & 8.4 \\
Total & 623 & 100.0 & & 100 & 14.9 \\
\hline
\end{tabular}

from the 623 examined falcons were compiled and statistically analyzed as shown in Table II. Although tuberculosis and poxvirus had a tendency to act as an agent, statistical analysis did not support this impression in this series of falcons. By contrast, it is clear from the statistical data that only two conditions are found to be elevated significantly in falcons with amyloidosis - bumble foot and chronic visceral gout. Which inflammatory events can defend falcons from the chronicity of inflammations (as perhaps in the different not identified falcon species) needs to be further examined.

\section{Recent, notably increased prevalence of amyloidosis in falcons}

The incidence of amyloidosis among the necropsied 100 falcons is shown in Figure 7. These data derived from the charts illustrate a notably steep increase in the prevalence of amyloidosis during the most recent time period spanning the years from 1996 to 2004 . The detailed contribution of this increase of the individual falcon species has not been examined yet. However, the overall prevalence of falcon amyloidosis suggests that the gyr falcons contributed most as compared with the other falcon species (Table I). 


\section{Quantification of falcon serum amyloid $A$ protein}

The first results of the dot immunoassay developed with the monoclonal AA antibody (mc29) revealed a sensitivity of $\sim 2 \mu \mathrm{g}$ f-SAA $/ \mathrm{ml}$ based on the highly and chemically characterized human AA (KIR) protein as a standard (determined on the intensity of the staining). Values above $20 \mu \mathrm{g} / \mathrm{ml}$ were considered pathologic, since the f-SAA values were below $10 \mu \mathrm{g} /$ $\mathrm{ml}$ in most healthy falcons. Comparing the sera of falcons with and without amyloidosis, the following data were found: The f-SAA values of the 38 falcons with AA amyloidosis were pathologically elevated in 36. By contrast, in the 15 apparently disease-free falcons, only one had elevated f-SAA values. This difference is statistically highly significant $(p<0.001)$. A more detailed account of this part is in progress.

Table II. Prevalence of inflammatory events in 523 falcons without amyloidosis (I) as compared to 100 falcons with amyloidosis (II) including statistical evaluation.

\begin{tabular}{|c|c|c|c|c|c|}
\hline \multirow[b]{2}{*}{ Diseases } & \multicolumn{2}{|l|}{ I } & \multicolumn{2}{|l|}{ II } & \multirow{2}{*}{$\begin{array}{c}\text { Significance }^{\mathrm{a}} \\
\text { for amyloid, } \\
\quad p \text {-value }\end{array}$} \\
\hline & Number & $\%$ & Number & $\%$ & \\
\hline Aspergillosis & 74 & 14.1 & 19 & 19 & 0.1724 \\
\hline Bumblefoot & 0 & 0 & 23 & 23 & $<0.001$ \\
\hline Chlamydiosis & 22 & 4.2 & 0 & 0 & \\
\hline Clostridiosis & 99 & 18.9 & 0 & 0 & \\
\hline Gout & 38 & 7.3 & 26 & 26 & 0.0074 \\
\hline Herpes virus & 43 & 8.2 & 0 & 0 & \\
\hline Intoxication & 5 & 1 & 0 & 0 & \\
\hline Paramyxovirus & 36 & 6.9 & 0 & 0 & \\
\hline Pasteurellosis & 2 & 0.4 & 0 & 0 & \\
\hline Parasites & 38 & 7.3 & 9 & 9 & $>0.3049$ \\
\hline Pneumonia & 3 & 0.6 & 0 & 0 & \\
\hline Poxvirus & 6 & 1.1 & 6 & 6 & 0.1203 \\
\hline Salmonellosis & 34 & 6.5 & 0 & 0 & \\
\hline Tuberculosis & 10 & 1.9 & 8 & 8 & 0.1447 \\
\hline Others & 113 & 21.6 & 9 & 9 & $<0.001$ \\
\hline Total & 523 & 100 & 100 & 100 & \\
\hline
\end{tabular}

${ }^{\mathrm{a}}$ Values given by fat italic indicates significance.

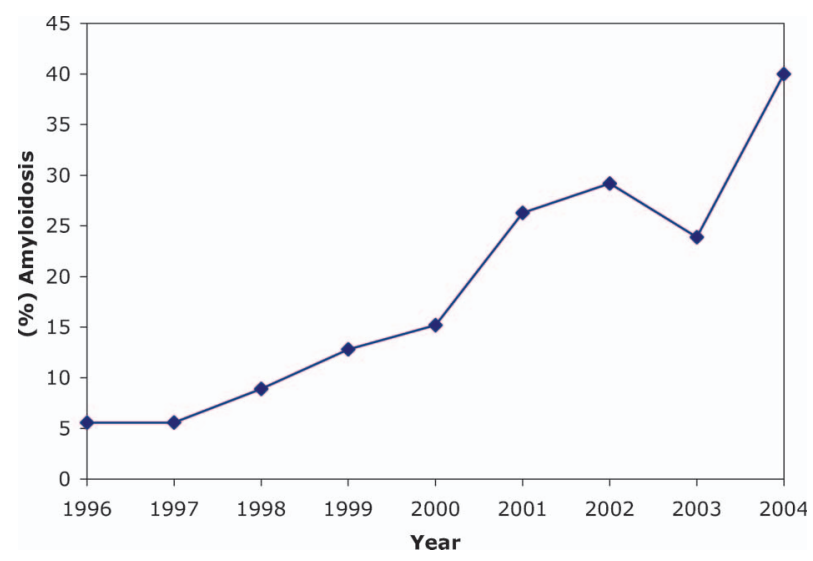

Figure 7. Increasing prevalence of AA amyloidosis in falcons during 1996-2004.

\section{Discussion}

This report establishes that a fatal disease in hunting falcons, which is new in Dubai, is based on the deposition of AA amyloid in various organs. The prevalence of systemic AA amyloidosis is a major cause of death in hunting falcons, because it was identified in $16 \%$ out of 623 necropsies from the UAE and neighboring states. In addition, this high prevalence of AA amyloidosis has increased more than fourfold during the years 1996-2004 (Figure 7), as taken from the charts.

The chemical nature of the predominant protein in falcon amyloid was identified immunohistochemically and established chemically by N-terminal amino acid sequence analysis. As the size of this AA-protein of $8 \mathrm{kDa}$ is smaller than that of its serum precursor $(11.0 \mathrm{kDa})$ as found in humans, limited proteolysis of $\mathrm{f}-\mathrm{SAA}$ can be inferred in the pathogenesis of the f-AA amyloidosis in line with the pathogenesis of AA amyloidosis in men [3,12,13] and in animals [10,21].

The main target organ of the falcon AA amyloidosis is the liver, which showed in many cases a characteristic green discoloration caused by bile stasis (Figure 2). Bile stasis has been described in inflammations, infections, neoplasia, toxic insults, and lipoidosis [55]. Now, inflammation with hepatic amyloidosis can be added to this list. The liver is followed by the kidneys, spleen, and adrenal glands, which is similar to the distribution in another bird, the duck, in which the liver is also reported to be the predominantly affected organ [27]. As the glomeruli are not generally the preferred target for amyloid in falcons, it can be assumed that the majority of falcons die from liver failure. This is in contrast to AAamyloidosis in humans (and other mammals), which leads to fatal renal failure in the majority of patients $[3,13]$. The major target of amyloid distribution varies in different species, as shown in Table III.

The amyloid distribution in falcons (and possibly in other birds) may indicate that the liver is most susceptible and/or that the causative agent inducing this disease could reside in the liver earlier and/or in a higher concentration than in other organs.

Table III. Main organ involvement of AA amyloid in different animals.

\begin{tabular}{lcc}
\hline Animal & Organ & Reference \\
\hline Cow & Kidney & 19 \\
Cheetah & Kidney & 56 \\
Hamster & Kidney & 57 \\
Horse & Digestive tract & 58 \\
Mink & Spleen & 59 \\
Duck & Liver & 27 \\
Dog & Joint & 15 \\
Chicken & Joint & 31 \\
\hline
\end{tabular}


Different susceptibility for acquiring AA amyloidosis has been observed among the different falcon species, with the highest found in gyr falcons. This difference was significant when compared with the non-gyr falcons. However, the prevalence of AA amyloidosis among the non-gyr falcon species was not significant, including that found in the gyr hybrids.

The latter finding of a reduction of the prevalence of amyloidosis in gyr hybrids points to a decisive resistance factor, which is being genetically transmitted by cross-breading. The nature and the action of this factor needs to be delineated. Hereditary transmission has been reported in cats [16] and dogs [60]. Autosomal dominant (and, in some syndromes, also recessive) transmission of amyloidosis has been reported in humans in several different hereditary amyloid classes [61,62], including AA amyloidosis, in which different genetic defects in proteins along the fever cascade have been described $[63,64]$.

Whether the cause of the falcon AA amyloidosis is based on a single mechanism and whether it follows some of the aforementioned patterns needs to be explored.

There may be contributions to amyloidosis from the fact that falcons are bred by in vitro fertilization, which may have compromised the immune system through the reduction of variability. Another possibility could be an altered structure of the f-SAA protein resulting in an increase of amyloidogenicity. One can also think of a genetic predisposition with the obviously higher response to stress in gyr falcons, which may also compromise immunity and thereby ensue in an increased susceptibility to infectious agents. A further possibility is contamination and ingestion of amyloid through a prion mechanism, as has been shown in several experimental systems [65]. It is worth mentioning that the French dish foie gras prepared from the amyloid-loaded liver of the Pecking duck contains AA fibrils that can accelerate the development of AA amyloidosis after ingestion through a prion-like mechanism in mice [66].

The cause of the AA amyloidosis in falcons is driven by long-standing inflammations with recurrent acute exacerbations as known from humans and animals $[2,3,4,10,13]$. Accordingly, the charts of the falcons revealed inflammations of various kinds (Table II). However, a significant increase of AA amyloidosis was detected only in bumble foot and visceral gout. Bumble foot in falcons is known to be caused by bacterial infections of foot paths due to permanent sitting. A similar syndrome with amyloidosis has been reported in puppies [67]. By contrast, tuberculosis, aspergillosis and poxvirus, although more prevalent in falcons with amyloidosis, were not statistically significant in this series - probably due to the low numbers of falcons examined. As bumble foot and visceral gout account for only a fraction of all amyloid cases, more infectious agents have to be assumed as suggested by the category 'others' in Table II. In this context, the report of Gierse [68] on inflammatory diseases in a large series of 5696 examined falcons demonstrates that various inflammatory agents are identified which may have also induced AA-amyloidosis in our series of falcons.

Various inflammations, tissue damages or neoplasias in humans and animals $[3,13]$ result in a steep increase in the concentration of serum amyloid A protein (SAA), a $12.5 \mathrm{kDa}$ serum protein that can lead in sustained inflammation to AA amyloidosis when during degradation of SAA to a $8.5 \mathrm{kDa} \mathrm{N}$-terminal hydrophobic fragment of SAA is transformed and deposited as AA amyloid in glycosamine-glycan-rich tissue structures [69]. SAA is monokine-induced in the liver and in several other extrahepatic tissues [70,71]. A similar mechanism is strongly indicated in falcons by the significant association of AA amyloidosis with chronic inflammations and the fragmented nature of f-AA (8.0 $\mathrm{kDa}$ ) which is most probably derived from f-SAA $(11.0 \mathrm{kDa})$ as reported here.

The risk to succumb to AA amyloidosis has been estimated through a semiquantitative test of f-SAA. It has been shown that this test can be used to distinguish falcons with an acute phase condition in amyloidotic birds from those without any acute phase condition. Because an increased f-SAA concentration will also be found in non-amyloidogenic inflammations of short duration, only a long-term $\mathrm{f}$ SAA increase will pose the falcons at risk, as has been established in humans [13,72] and animals [10]. Thus, the concentration of SAA could be used to distinguish falcons with a potential amyloidogenic inflammation from those falcons which are disease free. The latter falcons with a normal f-SAA level will therefore most probably not be as susceptible to succumb to AA amyloidosis, which is still an illness that is not yet curable without knowing its cause. In humans, various therapeutic options have been reviewed for AA amyloidosis $[4,5,13]$. In falcons, the therapy of the specific infections, of gout and bumble foot and others, will have to be considered first, monitored by f-SAA determination. In addition, the possible prevention of AA amyloidosis may come from the delineation of the possibility of a susceptibility factor in the gyr-falcon. This assumed factor was shown here to contribute significantly to the prevalence of AA amyloidosis in hunting falcons.

\section{Acknowledgements}

We are grateful to Drs. P. McKinney, A. Di Somma, J. Samour, T. Bailey, and A. Sharma for providing 
tissue, falcon sera, and clinical information, and to Prof. E. Gruys, Utrecht, The Netherlands, for his valuable advice and the three polyclonal anti-animal AA antisera. For technical assistance, we thank Mrs. R. Oos, Mrs. J. Lindermayer, amYmed (Martinsried), and Mr. R. Mentele and Mr. C. Vishwanathan (Max-Planck-Institute for Biochemistry); for assistance concerning the color images we thank Mrs. G. Schönhofer (Fotostelle, Max-Planck-Institute for Biochemistry, Martinsried) and Ms. Anne K.M. Linke, Munich. For electron microscopy, we thank Mrs. M. Braun, Max-Planck-Institute of Neurology, Martinsried. Laboratory space for establishing the quantitation of f-SAA was provided by courtesy of Prof. Dr. R. Huber, Max-Planck-Institute of Biochemistry, Martinsried and financial support of this project was provided by amYmed, Martinsried. For secretarial work we thank Mrs. A. Feix, amYmed, Martinsried. We are grateful to Dr. R. Padrtova, MSc, PhD, Nad Al Shiba Veterinary Hospital, Dubai, UAE for her multiple, expert statistical analyses. For never-ending encouragement and financial support to this project, the first author thanks her parents, Mrs. Gisela Hampel and Mr. Hans Hampel, to whom this article will be dedicated. Part of this account has been presented in the form of an abstract [73].

\section{References}

1. Frederik II of Hohenstaufen. De arte venandi cum avibus. Bibliotheca Vaticana, Pal. lat. 1071; f 79v/80v.

2. Benditt EP, Eriksen N. Chemical classes of amyloid substance. Am J Pathol 1971;65:231-249.

3. Glenner GG. Amyloid deposits and amyloidosis. The $\beta$-fibrillosis. N Engl J Med 1980;302:1283-1292 (see also 1333-1343).

4. Buxbaum JN. The systemic amyloidosis. Curr Opin Rheumatol 2004; 16:67-75.

5. Merlini G, Westermark P. The systemic amyloidoses: clearer understanding of the molecular mechanisms offers hope for more effective therapies. J Intern Med 2004;255:159-178.

6. Jakob W. Spontaneous amyloidosis of mammals. Vet Pathol 1971;8:292-306.

7. Linke RP, Hol PR, Gruys E, Geisel O, Nathrath WB, Trautwein G. Immunohistochemical identification and crossreactions of amyloid-A fibril protein in man and eleven other species. J Comp Pathol 1984;94:339-356.

8. Zschiesche W, Jakob W. Pathology of animal amyloidosis. Pharmacology 1989;41:49-83.

9. Xing Y, Higuchi K. Amyloid fibrils proteins. Mech Age Dev 2002;123:1625-1636.

10. Gruys E. Protein folding pathology in domestic animals. J Zhejiang Univ Sci 2004;10:1226-1238.

11. Puchtler H, Sweat F, Levine M. On the binding of Congo red by amyloid. J Histochem Cytochem 1962;10:355-364.

12. Husby G, Marhaug G, Dowton B, Sletten K, Sipe JD. Serum amyloid A (SAA): biochemistry, genetics and the pathogenesis of AA amyloidosis. Amyloid Int J Exp Clin Invest 1994;1:119 137.

13. Lachmann HJ, Goodman HJ, Gilbertson JA, Gallimore JR, Sabin CA, Gillmore JD, Hawkins PN. Natural history and outcome of AA amyloidosis. N Engl J Med 2007;356:2361-2371.
14. Westermark P, Johnson KH, Sletten K, Hayden DW. AAamyloidosis in dogs: partial amino acid sequence of protein AA and immunohistochemical cross-reactivity with human and cow AA-amyloid. Comp Biochem Physiol 1985;82:211-215.

15. Colbatzky F, Brunnberg L, Linke RP, Geisel O, Hermanns W. AA-like amyloid deposits confined to arthritic joints in two dogs with rheumatoid arthritis. J Comp Pathol 1991;105:331343.

16. Niewold TA, van der Linde-Sipman JS, Murphy C, Tooten PC, Gruys E. Familial amyloidosis in cats: Siamese and Abyssinian AA-proteins differ in primary sequence and pattern of deposition. Amyloid Int J Exp Clin Invest 1999;6:205-209.

17. Johnson KH, Sletten K, Werdin RE, Westermark GT, O'Brien TD, Westermark P. Amino acid sequence variations in protein AA of cats with high and low incidences of AA amyloidosis. Comp Biochem Physiol 1989;94:765-768.

18. Bergstrom J, Ueda M, Une Y, Sun X, Misumi S, Shoji S, Ando Y. Analysis of amyloid fibrils in the cheetah (Acinonyx jubatus). Amyloid J Protein Fold Disord 2006;13:93-98.

19. Hol PR, Langevrld JP, van Beuningen-Jansen EW, Veerkamp $\mathrm{JH}$, Gruys E. A second component in bovine AAamyloid fibrils not identical with protein AA is essential for AA-amyloid fibrillogenesis. Scand J Immunol 1984;20:53-60.

20. Tojo K, Tokuda T, Hoshii Y, Fu X, Higuchi K, Matsui T, Kametani F, Ikeda S. Unexpectedly high incidence of visceral AA-amyloidosis in slaughtered cattle in Japan. Amyloid J Protein Fold Disord 2005;12:103-108.

21. Syversen PV, Juul J, Marhaug G, Husby G, Sletten K. The primary structure of serum amyloid A protein in sheep. Comparison with serum amyloid A in other species. Scand J Immunol 1994;39:88-94.

22. Fernandez A, Mensua C, Biescas E, Lujan L. Clinicopathological features in ovine AA amyloidosis. Res Vet Sci 2003; 75:203-220.

23. Niewold TA, Murphy CL, Toussaint MJ, Solomon A, Gruys E. Chemical typing of porcine systemic amyloid as AAamyloid. Amyloid J Protein Fold Disord 2005;12:164-166.

24. Sletten K, Husebekk A, Husby G. The amino acid sequence of an amyloid fibril protein AA isolated from the horse. Scand J Immunol 1987;26:79-84.

25. Geisel O, Linke RP. Generalized AA-amyloidosis in two hares (Lepus europaeus) immunohistochemically identified using poly- and monoclonal antibodies. Vet Pathol 1988;25:391-393.

26. Shtrasburg S, Gal R, Gruys E, Perl S, Martin BM, Kaplan B, Koren R, Nyska A, Pras M, Livneh A. An ancillary tool for the diagnosis of amyloid A amyloidosis in a variety of domestic and wild animals. Vet Pathol 2005;42:132-139.

27. Gorevic PD, Greenwald M, Frangione B. The amino acid sequence of duck amyloid A protein. J Immunol 1977;118:1113-1118.

28. Ericsson LH, Eriksen N, Walsh KA, Benditt EP. Primary structure of duck amyloid protein A. The form deposited in tissues may be identical to its serum precursor. FEBS Lett 1987;218:11-16.

29. Guo JT, Aldrich CE, Mason WS, Pugh JC. Characterization of serum amyloid A protein mRNA expression and secondary amyloidosis in the domestic duck. Proc Natl Acad Sci USA 1996;93:14548-14553.

30. Kovacs BM, Szilagy L, Janan J, Rudas P. Serum amyloid A in geese; cloning and expression of recombinant protein. Amyloid J Protein Fold Disord 2005;121:109-114.

31. Landmann WJM, Sletten K, Koch CA, Tooten PC, Gruys E. Chicken joint amyloid protein is of Type AA: characterization of the amyloid protein. Scand J Immunol 1996;43:210-230.

32. Zschiesche W, Linke RP. Immunohistochemical characterization of spontaneous amyloidosis in captive birds as AA-type, using monoclonal and polyclonal anti-AA-antibodies against mammalian amyloid. Acta Histochem 1989;86:45-50. 
33. Zoellner A. Untersuchungen zur Amyloidose bei Zoo- und Wildvoegeln, sowie zur histo- und immunohistologischen Charakterisierung des aviaeren Amyloidproteins. Doctoral thesis, Freie Universitaet Berlin, Germany; 1997.

34. Ippen R, Schroeder H-D. Ein Beitrag zu den Erkrankungen der Zoovoegel. Verhandlungsberichte Erkrankungen der Zootiere 1972;14:11-27.

35. Romeis. Mikroskopische Technik; Hrsg. P.Boeck 1989;17. Auflage.

36. Linke RP. Highly sensitive diagnosis of amyloid and various amyloid syndromes using Congo red fluorescence. Virchows Arch 2000;436:439-448.

37. Linke RP. Monoclonal antibodies against amyloid fibril protein AA. Production, specificity and use for immunhistochemical localization and classification of AA-type amyloidosis. J Histochem Cytochem 1984;32:322-328.

38. Linke RP, Oos R, Wiegel N, Nathrath WBJ. Classification of amyloidosis: misdiagnosis by way of incomplete immunohistochemistry and how to prevent it. Acta Histochem 2006;108:197-208.

39. Linke RP, Geisel O, Mann K. Equine cutaneous amyloidosis derived from an immunoglobulin lambda-light chain. Immunohistochemical, immunochemical and chemical results. Biol Chem Hoppe Seyler 1990;372:835-843.

40. Platz SJ, Breuer W, Geisel O, Linke RP, Hermanns W. Identification of lambda light chain amyloid in eight canine and two feline extramedullary plasmacytomas. J Comp Pathol 1997;116:45-54.

41. Rowland PH, Linke RP. Immunohistochemical characterization of lamda light-chain-derived Amyloid in one feline and five canine plasma cell tumors. Vet Pathol 1994;31:390-393.

42. Linke RP, Heilmann KL, Nathrath WBJ, Eulitz M. Identification of amyloid A protein in a sporadic Muckle-Wells syndrome. $\mathrm{N}$-terminal amino acid sequence analysis after isolation from formalin-fixed tissue. Lab Invest 1983;48:698-704.

43. Hashimoto F, Horigome T, Kanbayashi M, Yoshida $\mathrm{K}$, Sugano H. An improved method for separation of lowmolecular-weight polypeptides by electrophoresis in sodium dodecyl sulphate-polyacrylamide gel. Anal Biochem 1983;129:192-199.

44. Towbin H, Staehelin T, Gordon J. Electrophoretic transfer of proteins from polyacrylamide gels to nitrocellulose sheets: procedure and some applications. Proc Natl Acad Sci USA 1992;76:4350-4354.

45. Eckerskorn C, Lottspeich F. Internal amino acid sequence analysis of proteins separated by gel electrophoresis after tryptic digestion in polyacrylamide matrix. Chromatographia 1989;28:92-94.

46. Patterson SD. From electrophoretically separated protein to identification: strategies for sequence and mass analysis. Anal Biochem 1994;221:1-15.

47. Edman P, Begg G. A protein sequenator. Eur J Biochem 1967;1:80-91.

48. Altschul SF, Madden TL, Schäffer AA, Zhang J, Zhang Z, Miller W, Lipman DJ. 'Gapped BLAST and PSI-BLAST': a new generation of protein database search programs. Nucleic Acids Res 1997;25:3389-3402.

49. Ogata F. Quantitative dot-blot enzyme immunoassay for serum amyloid A protein. J Immunol Methods 1989;116:131135.

50. Pras M, Schubert M, Zucker-Franklin D, Rimon A, Franklin EC. The characterization of soluble amyloid prepared in water. J Clin Invest 1968;47:924-933.

51. Zar JH. Biostatistical analysis. Upper Saddle River, NJ: Prentice-Hall Int.; 1996.

52. Rozsal L, Reiczigel J, Majoros G. Quantifying parasites in samples of hosts. J Parasitol 2000;86:228-232.
53. Wright JR, Calkins E, Humphrey RL. Potassium permanganate reaction in Amyloidosis. A histological method to assist in differentiating forms of this disease. Lab Invest 1977;36: 274-281.

54. Levin M, Franklin EC, Frangione B, Pras M. The amino acid sequence of major nonimmunoglobulin component of some amyloid fibrils. J Clin Invest 1972;51:2773-2776.

55. Harr, KE, Clinical chemistry of companion avian species: a review. Vet Clin Pathol 2002;31:140-151.

56. Papendick RE, Munson L, O'Brien TD, Johnson KH. Systemic AA amyloidosis in captive cheetahs (Acinonyx jubatus). Vet Pathol 1997;34:549-556.

57. Murphy JC, Fox JG, Niemi SM. Nephrotic syndrome associated with renal amyloidosis in a colony of Syrian hamsters. J Vet Med Assoc 1984;185:1359-1362.

58. Hayden DW, Johnson $\mathrm{KH}$, Wolf CB, Westermark P. AA amyloid-associated gastroenteropathy in a horse. J Comp Pathol 1988;98:195-204.

59. Wien TN, Sørby R, Omtvedt LA, Landsverk T, Husby G. Kinetics of glysaminoglycan deposition in splenic AA amyloidosis induced in mink. Scand J Immunol 2004;60: 600-608.

60. DiBartola SP, Tarr MJ, Webb DM, Giger U. Familial renal amyloidosis in Chinese Shar Pei dogs. J Am Vet Med Assoc 1990;197:483-487.

61. Buxbaum JN, Tagoe CE. The genetics of the amyloidosis. Annu Rev Med 2000;51:543-569.

62. Benson MD. The hereditary amyloidosis. Best Pract Res Clin Rheumatol 2003;17:909-927.

63. Buxbaum JN. The systemic amyloidoses. Curr Opin Rheumatol 2004;16:67-75.

64. Hull KM, Drewe E, Aksentijevich I, Singh HK, Wong K, McDermott EM, Dean J, Powell RJ, Kastner DL. The TNF receptor-associated periodic syndrome (TRAPS). Emerging concepts of an autoinflammatory disorder. Medicine 2002;81:349-368.

65. Elliott-Bryant R, Cathcart ES. Amyloid enhancing factor and dietary transmission in accelerated amyloid A amyloidosis. Clin Immunol Immunopathol 1998;88:65-69.

66. Landmark K, Westermark GT, Nyström S, Murphy CL, Solomon A, Westermark P. Transmissibility of systemic amyloidosis by a prion-like mechanism. Proc Natl Acad Sci USA 2002;99:6979-6984.

67. Gruys E. Inflammatory syndrome of footpaths in puppies and AA-amyloidosis. Vet Rec 1996;138:264-268.

68. Gierse S. Die wichtigsten Infektionskrankheiten bei Falken (Falconidae) und die Bedeutung der Beutevögel als Überträger. Doctoral Thesis, Universitaet Munich, Germany, 2001.

69. Snow AD, Willmer J, Kisilevsky R. Sulfated glycoaminoglycans: a common constituent of all amyloids? Lab Invest 1987;56:120-123.

70. Selinger MJ, McAdam KP, Kaplan MM, Sipe JD, Vogel SN, Rosenstreich DL. Monokine-induced synthesis of serum amyloid A protein by hepatocytes. Nature 1980;285:498-500.

71. Urieli-Shoval S, Linke RP, Matzner Y. Expression and function of serum amyloid A, a major acute phase protein, in normal and disease states. Curr Opin Hematol 2000;7: 64-69.

72. Gilmore JD, Lovat LB, Persey MR, Pepys MB, Hawkins PN. Amyloid load and clinical outcome in AA amyloidosis in relation to circulating concentration of serum amyloid A protein. Lancet 2001;358:24-29.

73. Hampel MR, Wernery U, Kenne J, Linke RP. AA-amyloidosis in hunting falcons in the United Arab Emirates. Poster No. 54 at the Xth International Symposium on Amyloid and Amyloidosis. April 18-22, 2004. Tours, France. 